\title{
Association between quality of life and severity of menopausal symptoms among Saudi women in Al-Ahsa
}

\author{
Ola Mousa*1,2, Fatemah M. Alkhars², Mashael T. Al Shawaf ${ }^{2}$, Enas A. Al Omran², Rawan A. Alkhawajah², Jehan Abd \\ Elrahem Mohamed ${ }^{1}$ \\ ${ }^{1}$ Faculty of Nursing, Minia University, Egypt \\ ${ }^{2}$ College of Applied Medical Sciences, King Faisal university, Saudi Arabia
}

Received: May 18, 2021

DOI: $10.5430 /$ jnep.v11n12p82
Accepted: August 1, 2021

Online Published: August 27, 2021

\begin{abstract}
Background and objective: Menopause is not an illness. It is a normal physiologic process at the time that marks the end of the menstrual cycles. The severity, frequency, duration, and impact of these menopausal symptoms vary from woman to woman according to their age, and they affect the overall quality of life. The aim of this study is to verify the severity of menopausal symptoms experienced by Saudi women in Al Ahsa, and to identify the association between the severity of menopausal symptoms and their effects on the quality of life of Saudi women.

Methods: An analytical cross-sectional study involved 427 women aged 45-60 years old. They were randomly collected by researchers who interviewed them in outpatient clinics and obstetrics and gynecology wards from 6 hospitals by using the Menopause Rating Scale (MRS) questionnaire and the Menopause Specific Quality of Life (MENQOL) questionnaire between February 15, 2021 and May 15, 2021.

Results: The average age of participants was between 45-49. The MRS shows that mild symptoms were found in $47.8 \%$ of participants, while severe symptoms were $10.6 \%$. The most common symptoms were physical and somatic. The Menopause Specific Quality of Life shows that $52.2 \%$ of the participants suffer from mild bothersome, while $7.5 \%$ have extremely bothersome. There was a strong positive association between menopause specific quality of life, and menopausal symptoms.

Conclusions: There was a positive correlation between menopausal symptoms and the quality of life of women. Menopausal symptoms have a negative impact on the quality of women's lives. Therefore, the policy makers in the ministry of health could strengthen providing health programmes and health services to women in this age group, besides women in the reproductive age. This can be accomplished by including modules related to the special health needs of menopausal women in the primary center's health programs.
\end{abstract}

Key Words: Menopause, Menopause rating scale, Quality of life, Saudi women, Symptoms

\section{INTRODUCTION}

Menopause is not an illness. It is a normal physiologic process, the time that marks the end of the menstrual cycles. ${ }^{[1]}$ Menopause is an ordinary event in women's lives. Several studies have revealed that these symptoms have a negative impact on women's quality of life. ${ }^{[2]}$ The menopausal transition begins at between 45 and 55 years old. Natural menopause occurs at an average age of 48.8 years. ${ }^{[3]}$

*Correspondence: Ola Mousa; Email: olaessam1977@yahoo.com; Address: Faculty of Nursing, Minia University, Egypt. 
Menopause is characterized by an irregular menstrual cycle, trouble sleeping, night sweats, hot flashes, feeling irritable, anxious or depressed, and marked hormonal fluctuations. ${ }^{[4]}$ More than $80 \%$ of women report various somatic, psychological, and sexual symptoms because of deficiency of sex hormones. ${ }^{[5]}$ Some of the emotional changes that women undergo menopause include irritability, sleep disturbance, feelings of sadness, anxiety, difficulty concentrating, aggressiveness, and mood changes. ${ }^{[6]}$

The decline in estrogen and progesterone hormones causes changes in women's bodies and low sexual drive. Menopausal women become less interested in sex. Also, deficiency of sex hormones, estrogen and progesterone, causes a drop in blood supply to the vagina which may affect the vagina and make it dry. Therefore, menopause women will not be comfortable during sexual intercourse. ${ }^{[7]}$

After menopause, there are increased health risks, such as osteoporosis, which causes bones to become fragile and weak as a result of a deficiency in calcium and vitamin $\mathrm{D}$, which makes menopausal women more prone to falls, fractures, and injuries. Also, there is a possibility of increased cardiovascular diseases, which is the leading cause of death in women. ${ }^{[4]}$ Menopausal symptoms have an impact on quality of life. ${ }^{[8]}$ The severity, frequency, duration, and impact of these menopausal symptoms vary from woman to woman according to their age. ${ }^{[9]}$

Many studies indicated that the prevalence and specific experienced symptoms differed between each woman based on their menopausal status. ${ }^{[10]}$ The greatest impact on the quality of life was the sexual domain, followed by the physical, psychological, and vasomotor. ${ }^{[11]}$ Most menopausal and postmenopausal women have effects on sexual domains. Half of the women at menopausal age had low physical activity, which affected the quality of life during mid-life. ${ }^{[12]}$

The professional status of individuals was significantly affected in the assessment of the quality of life in physical health, psychological, environmental, social relationships and general satisfaction with health status. ${ }^{[13]}$ Therefore, the study will be carried out to analyze how the intensity of experienced symptoms at menopause age affects the quality of life among Saudi women in Al Ahsa community.

\section{Aim of the study}

The aim of this study is to verify the severity of menopausal symptoms experienced by Saudi women in Al Ahsa, and to identify the association between the severity of menopausal symptoms and their effects on the quality of life of Saudi women.

\section{MAterials AND MethodS}

\subsection{Study design}

An analytic cross-sectional study was used to determine the association between severity of menopausal symptoms experienced and quality of life among Saudi women in Al-Ahsa, between February 15, 2021 and May 15, 2021.

\subsection{Study area/setting}

Six hospitals (three governmental and three private hospitals) in $\mathrm{Al}$-Ahsa.

\subsection{Study subject}

Inclusion: Women who are 45-60 years old at menopause age have started or not started menopausal symptoms.

\subsection{Sample size}

The sample was collected from women who visited the outpatient department clinics and obstetrics and gynecology wards of six hospitals (three governmental and three private hospitals). The average number of patients each day is near to 3,00 patients/day. The inclusion criteria consisted of women between the ages of 45-60 years who had given consent to participate in this study. The woman in antenatal period or lactating women, women with uncontrolled medical conditions such as hypertension, diabetes mellitus, or heart disease were excluded from the study, as were women who were undergoing cancer treatment or were in remission, or who had a history of hormone replacement therapy, or who had noncommunicable diseases or polycystic ovary syndrome. The sample size was calculated by a sample size calculator. There should be 384 women at menopause age. It was calculated by assuming the proportion of women with menopausal symptoms to be $50 \%$. The researchers added a nonresponse rate of $20 \%$, so the sample required to be collected was 460 participants.

\subsection{Ethical considerations}

Ethical approval was obtained from the IRB at King Fahd Hospital Number 03-36-2021. An informed participation consent letter that clarifies the objectives and purpose of the study was given along with a self-administered questionnaire. Subjects are given free to decide whether to participate in study or not. Anonymity, privacy, and confidentiality of participants will be protected from unauthorized access, use, and disclosure.

\subsection{Data collection methods, instruments used, measure- ments}

Data was collected through interviews by the researchers. A tool for data collection is a questionnaire. The questionnaire has 3 sections. The first section is the demographic data of 
participants. The second section is the Menopause Rating Scale (MRS) related questionnaire as a basis for assessing the severity of menopausal symptoms in this study. The MRS is internationally accepted. The scale was developed in 1996 by the Berlin Epidemiology and Health Research Center. ${ }^{[14]}$ The scale contained 11 questions about menopausal symptoms and the rating of severity was marked from 0 (which means none) to 4 (which means very severe). The third section is the Menopause Specific Quality of Life (MENQOL) Form. The MENQOL form was introduced in 1996 to assess health- related quality of life in the menopausal period. It is used to assess the effect of menopausal symptoms on the quality of life. It contains 29 items on a Likert-scale. As a specific symptom is rated as present or not present, if present, how bothersome is it on a 0 (not bothersome) to 6 (extremely bothersome) scale. ${ }^{[15]}$

\subsection{Data management and analysis}

The data obtained was analyzed using the statistical package for social sciences (SPSS). Descriptive data will be presented using tables, graphs, and charts.

\section{RESUlts}

The researchers interviewed 460 participants and asked them to fill out the questionnaire. The complete questionnaire was collected from 427 participants, with a response rate of $92.8 \%$.

Table 1 shows the percentage distribution of the studied sample regarding their demographic characteristics. The majority of the responses were 303 (71\%) collected from governmental hospitals. However, more than half of the participants' $293(68.6 \%)$ ages were between 45 and 49 years old. More than half of the participants' $229(53.6 \%)$ educational level was secondary school. However, $322(75.4 \%)$ of the women in the study were married. Moreover, half of the participants were not working. In relation to Body Mass Index, it was noticed that $156(36.5 \%)$ were overweight, and $132(30.9 \%)$ were normal weight. Regarding smoking, 409 (95.8\%) were nonsmokers.

Table 1. Participants' demographic data

\begin{tabular}{|c|c|c|}
\hline Items & No. & $\%$ \\
\hline \multicolumn{3}{|l|}{ Hospital type } \\
\hline Govern & 303 & 71.0 \\
\hline Private & 124 & 29.0 \\
\hline \multicolumn{3}{|l|}{ Age/years } \\
\hline $45-49$ & 293 & 68.6 \\
\hline $50-55$ & 80 & 18.7 \\
\hline More than 55 & 54 & 12.6 \\
\hline \multicolumn{3}{|l|}{ Educational level } \\
\hline High school & 229 & 53.6 \\
\hline College \& above & 198 & 46.4 \\
\hline \multicolumn{3}{|l|}{ Marital status } \\
\hline Married & 322 & 75.4 \\
\hline Single & 56 & 13.1 \\
\hline Widowed & 25 & 5.9 \\
\hline Divorced & 24 & 5.6 \\
\hline \multicolumn{3}{|l|}{ Occupation } \\
\hline Non-employee & 217 & 50.8 \\
\hline Employee & 210 & 49.2 \\
\hline \multicolumn{3}{|l|}{ BMI } \\
\hline Underweight "BMI is less than 18.5" & 4 & 0.9 \\
\hline Normal "BMI is 18.5 to $<25$ ” & 132 & 30.9 \\
\hline Overweight "BMI is 25.0 to < 30 " & 156 & 36.5 \\
\hline Obese Class I "BMI of 30 to $<35$ ” & 114 & 26.7 \\
\hline Obese Class II "BMI of 35 to $<40$ " & 21 & 4.9 \\
\hline \multicolumn{3}{|l|}{ Smoking habits } \\
\hline No & 409 & 95.8 \\
\hline E-cigarette & 12 & 2.8 \\
\hline Ordinary cigarette & 6 & 1.4 \\
\hline
\end{tabular}

Figure 1 shows that mild symptoms were found in 204 $(47.8 \%)$ of the participants, while severe symptoms were found in $45(10.6 \%)$.

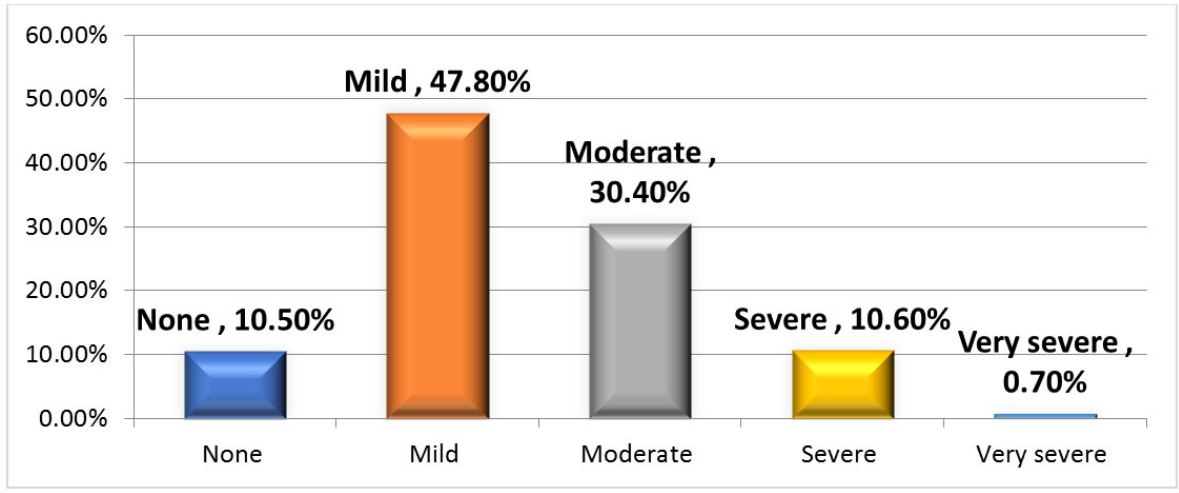

Figure 1. Severity of menopausal symptoms among participants 
Table 2 shows the menopausal symptoms. The most common symptoms were physical and somatic, which include "physical, joint and muscular discomfort, pain and weakness". It was obvious that common psycho-social symptoms were in the second level, which included "sleep problems, depressive mood, irritability and anxiety". In the third level, it was the urogenital symptoms, which include "sexual problems, bladder problems, and dryness of the vagina". The last level was for vasomotor symptoms, which include "night sweats, hot flashes, and flushes".

Figure 2 shows the Menopause Specific Quality of Life (MENQOL) level among participants. It was clear that more than half of the participants $223(52.2 \%)$ suffered from mild bothersome, while 32 (7.5\%) had extremely bothersome.

Table 3 reports that there was a highly statistically signifi- cant difference between age and the severity of menopausal symptoms. The severity increases with age increasing. The same fact occurred for marital status and BMI. There were no statistically significant differences between occupation or smoking habits and the severity of symptoms. It was clear that the symptoms seemed to be moderate to severe in the women over 55 age group, non-employment group, and obese women.

Table 2. Menopausal symptoms "Menopause Rating Scale"

\begin{tabular}{lll}
\hline & Min-max & Mean \pm SD \\
\hline Vasomotor & $0.0-8.00$ & $1.9 \pm 2.0$ \\
Psycho-Social & $0.0-20.0$ & $6.6 \pm 4.8$ \\
Physical and Somatic & $0.0-47.00$ & $19.2 \pm 11.2$ \\
Urogenital & $0.0-9.00$ & $3.1 \pm 2.7$ \\
\hline
\end{tabular}

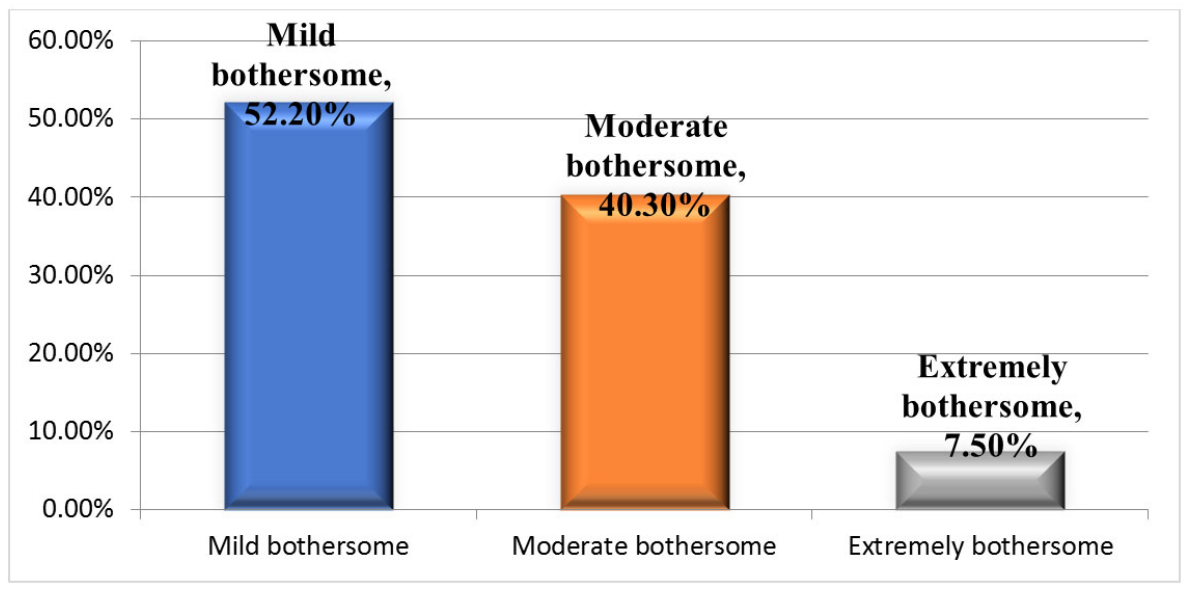

Figure 2. Menopause specific quality of life level

Table 5 shows that there was a significant relationship between the severity of the symptoms and the quality of life. It was noticed that the severity of symptoms was bothersome to the quality of women's lives. It was obvious that $59.4 \%$ of the participants who had extremely bothersome had severe menopausal symptoms and $59.3 \%$ of the participants who had moderately bothersome had moderate menopause symptoms with a $p$-value $<.0001$.

\section{Discussion}

Menopause is a critical matter in all women's lives. Experiencing menopausal symptoms may affect their quality of life. The current study aimed to verify the severity of menopausal symptoms experienced by Saudi women in Al Ahsa, and to identify the association between the severity of symptoms and their effects on the quality of life of Saudi women. More than half of the participants' (68.6\%) ages were between 45 and 49 years old. More than half of the participants' $(53.6 \%)$ educational level was secondary school. These results contrast with another study by Nisar N, which reported that most of the women included in their study were either illiterate or studied up to primary school. ${ }^{[16]}$ These differences may be due to community changes in relation to education improvement in Saudi Arabia.

In the present study, the most common symptoms were physical and somatic, which included "physical, joint and muscular discomfort, pain and weakness". It was obvious that common psycho-social symptoms were in the second level, which included "sleep problems, depressive mood, irritability and anxiety". In the third level, it was the urogenital symptoms, which included "sexual problems, bladder problems, and dryness of the vagina". The last level was for vasomotor symptoms, which include "night sweats, hot flushes, and flushing". These results were different from another study which reported that symptoms in all fields of physical, psychological and urogenital had a higher frequency in 
postmenopausal women. ${ }^{[2]}$ The higher prevalence of joint current study may be clarified by the characteristics of local and muscle discomfort than vasomotor like flushing in the weather and physical activity limitations for women in this community.

Table 3. Participants' characteristics and prevalence of menopausal symptoms

\begin{tabular}{|c|c|c|c|c|c|c|c|c|c|}
\hline \multirow{3}{*}{ Items } & \multirow{3}{*}{ No. } & \multicolumn{6}{|c|}{ MRS } & \multirow{2}{*}{\multicolumn{2}{|c|}{ Test of significance }} \\
\hline & & \multicolumn{2}{|c|}{$\begin{array}{l}\text { No } \\
(n=45)\end{array}$} & \multicolumn{2}{|c|}{$\begin{array}{l}\text { Mild } \\
(n=204)\end{array}$} & \multicolumn{2}{|c|}{$\begin{array}{l}\text { Moderate to very } \\
\text { severe }(n=178)\end{array}$} & & \\
\hline & & No. & $\%$ & No. & $\%$ & No. & $\%$ & $\chi^{2}$ & $p$-Value \\
\hline \multicolumn{10}{|l|}{ Age/years } \\
\hline $45<49$ & 293 & 45 & 15.4 & 146 & 49.8 & 102 & 34.8 & \multirow{3}{*}{32.772} & \multirow{3}{*}{$.0001 * *$} \\
\hline $50-<55$ & 80 & 0 & .0 & 37 & 46.3 & 43 & 53.8 & & \\
\hline More than 55 & 54 & 0 & .0 & 21 & 38.9 & 33 & 61.1 & & \\
\hline \multicolumn{8}{|l|}{ Marital status } & \multirow{5}{*}{20.714} & \multirow{5}{*}{$.002 * *$} \\
\hline Married & 322 & 27 & 8.4 & 161 & 50.0 & 134 & 41.6 & & \\
\hline Single & 56 & 11 & 19.6 & 23 & 41.1 & 22 & 39.3 & & \\
\hline Widowed & 25 & 0 & .0 & 10 & 40.0 & 15 & 60.0 & & \\
\hline Divorced & 24 & 7 & 29.2 & 10 & 41.7 & 7 & 29.2 & & \\
\hline \multicolumn{8}{|l|}{ Occupation } & \multirow{3}{*}{4.012} & \multirow{3}{*}{$.135^{\mathrm{NS}}$} \\
\hline Non employee & 217 & 18 & 8.3 & 100 & 46.1 & 99 & 45.6 & & \\
\hline Employee & 210 & 27 & 12.9 & 104 & 49.5 & 79 & 37.6 & & \\
\hline \multicolumn{8}{|l|}{ BMI } & \multirow{6}{*}{44.073} & \multirow{6}{*}{$.0001 * *$} \\
\hline Underweight & 4 & 0 & .0 & 4 & 100.0 & 0 & .0 & & \\
\hline Normal & 132 & 28 & 21.2 & 61 & 46.2 & 43 & 32.6 & & \\
\hline Overweight & 156 & 8 & 5.1 & 88 & 56.4 & 60 & 38.5 & & \\
\hline Obese Class I & 114 & 9 & 7.9 & 46 & 40.4 & 59 & 51.8 & & \\
\hline Obese Class II & 21 & 0 & .0 & 5 & 23.8 & 16 & 76.2 & & \\
\hline \multicolumn{8}{|l|}{ Smoking habits } & \multirow{4}{*}{2.312} & \multirow{4}{*}{$.679^{\mathrm{NS}}$} \\
\hline No & 409 & 45 & 11.0 & 195 & 47.7 & 169 & 41.3 & & \\
\hline E- cigarette & 12 & 0 & .0 & 6 & 50.0 & 6 & 50.0 & & \\
\hline Ordinary cigarette & 6 & 0 & .0 & 3 & 50.0 & 3 & 50.0 & & \\
\hline
\end{tabular}

Table 4. Correlation between the studied sample age, menopause symptoms, menopause specific quality of life and its domain

\begin{tabular}{|c|c|c|c|c|c|c|c|}
\hline & & Age & Vasomotor & Psychosocial & Physical & Sexual & Total MENQOL \\
\hline \multirow[t]{2}{*}{ Age } & $\mathrm{R}$ & 1 & & & & & \\
\hline & $p$-Value & & & & & & \\
\hline \multirow[t]{2}{*}{ Vasomotor } & $\mathrm{R}$ & $.258^{* *}$ & 1 & & & & \\
\hline & $p$-Value & .000 & & & & & \\
\hline \multirow[t]{2}{*}{ Psychosocial } & $\mathrm{R}$ & $.098^{*}$ & $.418^{* *}$ & 1 & & & \\
\hline & $p$-Value & .044 & .000 & & & & \\
\hline \multirow[t]{2}{*}{ Physical } & $\mathrm{R}$ & $.243^{* *}$ & $.416^{* *}$ & $.647^{* *}$ & 1 & & \\
\hline & $p$-Value & .000 & .000 & .000 & & & \\
\hline \multirow[t]{2}{*}{ Sexual } & $\mathrm{R}$ & $.350^{* *}$ & $.474^{* *}$ & $.410^{* *}$ & $.619^{* *}$ & 1 & \\
\hline & $p$-Value & .000 & .000 & .000 & .000 & & \\
\hline Total & $\mathrm{R}$ & $.265^{* *}$ & $.566^{* *}$ & $.794^{* *}$ & $.956^{* *}$ & $.714^{* *}$ & 1 \\
\hline MENQOL & $p$-Value & .000 & .000 & .000 & .000 & .000 & \\
\hline \multirow[t]{2}{*}{ Total MRS } & $\mathrm{R}$ & $.225^{* *}$ & $.503^{* *}$ & $.727^{* *}$ & $.803^{* *}$ & $.610^{* *}$ & $.860^{* *}$ \\
\hline & $p$-Value & .000 & .000 & .000 & .000 & .000 & .000 \\
\hline
\end{tabular}

${ }^{* *}$ Correlation is significant at the 0.01 level (2-tailed). ${ }^{*}$ Correlation is significant at the 0.05 level (2-tailed). 
Table 5. The relation between total menopause specific quality of life and menopausal symptoms

\begin{tabular}{|c|c|c|c|c|c|c|c|c|}
\hline \multirow{3}{*}{ MRS } & \multicolumn{6}{|c|}{ MENQOL } & & \\
\hline & \multicolumn{2}{|c|}{$\begin{array}{l}\text { Mild bothersome } \\
(\mathrm{n}=\mathbf{2 2 3})\end{array}$} & \multicolumn{2}{|c|}{$\begin{array}{l}\text { Moderate bothersome } \\
(n=172)\end{array}$} & \multicolumn{2}{|c|}{$\begin{array}{l}\text { Extremely bothersome } \\
(\mathrm{n}=32)\end{array}$} & \multicolumn{2}{|c|}{ Test of significance } \\
\hline & No. & $\%$ & No. & $\%$ & No. & $\%$ & $\chi^{2}$ & $p$-value \\
\hline None & 45 & 20.2 & 0 & .0 & 0 & .0 & & \\
\hline Mild Symptoms & 160 & 71.7 & 44 & 25.6 & 0 & .0 & & \\
\hline Moderate Symptoms & 18 & 8.1 & 102 & 59.3 & 10 & 31.3 & 321.103 & $.0001^{*}$ \\
\hline Severe Symptoms & 0 & .0 & 26 & 15.1 & 19 & 59.4 & & \\
\hline Very severe & 0 & .0 & 0 & .0 & 3 & 9.4 & & \\
\hline
\end{tabular}

In the current study, there was a high statistically significant difference between age, marital status, and BMI and the severity of menopausal symptoms. It is in the same line as another study reported that obese women experienced more severe symptoms compared to those with normal body mass index. ${ }^{[17]}$ Another study showed that there was no statistical association between BMI and severity of menopausal symptoms. ${ }^{[18]}$ In contrast with the present study findings related to age and severity of symptoms, the study of De Lorenzi and collaborators reported that the symptoms decreased as age increased, but a significant statistical correlation was not confirmed ${ }^{[19]}$ Another study confirmed that females aged 60 years had less opportunity to suffer from moderate to severe menopausal symptoms. ${ }^{[20]}$ It may be related to the differences in demographic characteristics between the study participants.

The present study reported no statistically significant differences between occupation or smoking habits and the severity of symptoms. It was contradictory with another study that reported that the prevalence of housewives with moderate to severe symptoms was approximately 50\% greater than that detected in women who worked. ${ }^{[21]}$ The study in Spain reported that smoking women had a higher occurrence of moderate to severe symptoms than nonsmokers. ${ }^{[22]}$ In a previous French study, severe symptoms were associated with smoking. ${ }^{[23]}$ These dissimilarities may be due to the smaller number of smoking women in this study compared with the other studies and the lower number of employed women.

The present study revealed that there was a significant relationship between the severity of the symptoms and the quality of life. It was clear that more than half of the participants $(52.2 \%)$ suffered from mild bothersome, while $(7.5 \%)$ had extremely bothersome. It was noticed that the severity of symptoms bothersome the quality of women's lives. These results were in agreement with many studies which reported that QoL is negatively associated with the severity of menopausal symptoms. ${ }^{[24-26]}$ These agreements may be caused by the fact that menopause affects all aspects of women's health, and many studies have shown that menopausal women's quality of life is threatened by menopausal symptoms.

\section{Conclusion}

There was a positive correlation between menopause related symptoms and the quality of life of women. Menopausal symptoms have a negative impact on the quality of women's lives. Therefore, the policy makers in the ministry of health could strengthen providing health programmes and health services to women in this age group, besides women in the reproductive age. This can be accomplished by including modules related to the special health needs of menopausal women in the primary center's health programs.

\section{Conflicts of InTEREST Disclosure}

The authors declare that they have no conflict of interest.

\section{REFERENCES}

[1] Al Quaiz J, Tayel S, Habib F. Assessment of Symptoms of Menopause and Their Severity Among Saudi Women in Riyadh. Annals of Saudi Medicine.com. 2013. Available from: https://www annsaudime d.net/doi/10.5144/0256-4947.2013.63

[2] Masjoudi M, Amjadi MA, Leyli E. Severity and Frequency of Menopausal Symptoms in Middle Aged Women, Rasht, Iran. Journal of clinical and diagnostic research: JCDR. 2017; 11(8): QC17-QC21. PMid:28969213 https://doi.org/10.7860/JCDR/2017/2699
4.10515

[3] AlShahrani AS, Faraj S, Alhargan A, et al. Factors affecting age at menopause among Saudi women in riyadh, Sa: a cross-sectional study. Fam Med Prim Care Rev. 2018; 20(1): 55-60. Available from: http://cejsh.icm.edu.pl/cejsh/element/bwmeta1.ele ment.desklight-fe1f678f-8b0f-47bd-9510-abaac073d74 d/c/09_FM_PCR_1_18_-_09_-_Shahrani_Al_-_Factors_af fecting.pdf

[4] AlDughaither A, AlMutairy H, AlAteeq M. Menopausal symptoms 
and quality of life among Saudi women visiting primary care clinics in Riyadh, Saudi Arabia. Int J Womens Health. 2015; 7: 645-653. PMid:26170720 https://doi .org/10.2147/IJWH. S84709

[5] Abd Elazim H, Lamadah S, Al Zamil L. Quality of Life Among Menopausal Women. International Journal of Reproduction, Contraception, Obstetrics and Gynecology.com. 2014. Available from: https://core.ac.uk/download/pdf/234659948.pdf

[6] Johnson T. The Emotional Roller Coaster of Menopause. Webmd.com. 2019. Available from: https://www.webmd.com/ menopause/guide/emotional-roller-coaster

[7] Johnson T. Sex and Menopause. Webmd.com. 2020. Available from: https://www. webmd.com/menopause/guide/sex-men opause\#1

[8] Asadi M, Jouyandeh Z, Nayebzadeh F. Prevalence of menopause symptoms among Iranian women. Journal of Family and Reproductive Health. 2012; 6(1): 1-3.

[9] Brown M. 11 Natural Ways to Reduce Symptoms of Menopause. Healthlinecom. 2016. Available from: https://www . healthline .com/nutrition/11-natural-menopause-tips

[10] Yisma E, Eshetu N, Dessalegn B. Prevalence and severity of menopause symptoms among peri menopausal and post menopausal women aged 30-49 years in Gulele sub- city of Addis Ababa, Ethiopia. BMC Women's Health. 2018. Available from: https://bmcwomenshealth.biomedcentral.com/arti cles/10.1186/s12905-017-0484-x

[11] Ibrahim M, Ghoneim MH, Madny HE, et al. The effect of menopausal symptoms on the quality of life among postmenopausal Egyptian women. Taylor \& Francis Journals. 2019. Available from: https://www.tandfonline.com/doi/full/10.1080/1 3697137.2019 .1656185 ? $\mathrm{c} c r o l l=$ top\&needAccess=true

[12] El Hajj A, Wardy N, Haidar S, et al. Menopausal symptoms, physical activity level and quality of life of women living in the Mediterranean region. PLOS ONE. 2020. Available from: https://journals.plos.org/plosone/article/file ?id=10.1371/journal . pone .0230515\&type=printable

[13] Szlachetka Z, Stasiak E, Drzewicka R. Intensity of menopausal symptoms and quality of life in climacteric women. Prz Menopauzalny. 2019 Dec; 18(4): 217-221. Available from: https://www.ncbi.n lm.nih.gov/pmc/articles/PMC7045359/\#_ffn_sectitle PMid:32132885 https://doi.org/10.5114/pm.2019.93113

[14] Koyuncu T, Unsal A, Didem A. Evaluation of the Effectiveness of Health Education on Menopause Symptoms and Knowledge and Attitude in Terms of Menopause. Europe PMC. 2018. Available from: https://europepmc.org/article/pmc/pmc7325820

[15] Radtke J, Terhorst L, Cohen S. The Menopause-Specific Quality of Life (MENQOL) Questionnaire: Psychometric Evalua- tion among Breast Cancer Survivors. Pub med. 2012. Available from: https://www.ncbi.nlm.nih.gov/pmc/articles/PMC3 017657/\#__ffn_sectitle

[16] Nisar N, Sohoo NA. Frequency of menopausal symptoms and their impact on the quality of life of women: a hospital-based survey. $\mathrm{J}$ Pak Med Assoc. 2009 Nov; 59(11): 752-6.

[17] Alquaiz JM, Siddiqui AR, Tayel SA, et al. Determinants of severity of menopausal symptoms among Saudi women in Riyadh city. Climacteric. 2014; 17(1): 71-8. PMid:23971880 https://doi.org/ $10.3109 / 13697137.2013 .815161$

[18] Capistrano E, Dombek K, da Costa A, et al. Factors associated with the severity of menopausal symptoms in postmenopausal Brazilian women. Reprodução \& Climatério. 2015; 30(2): 70-76. https : //doi.org/10.1016/j.recli.2015.09.002

[19] De Lorenzi DRS, Danelon C, Saciloto B, et al. Fatores indicadores da sintomatologia climatérica? Rev Bras Ginecol Obstet. 2005; 27: 12-9. https://doi.org/10.1590/S0100-72032005000100004

[20] Silveira ILD, Petronilo PA, Souza MD, et al. Prevalência de sintomas do climatério em mulheres dos meios rural e urbano no Rio Grande do Norte, Brasil. Rev Bras Ginecol Obstet. 2007; 29: 420-7. https://doi.org/10.1590/S0100-72032007000800006

[21] Malheiros ES, Chein MB, Silva DS, et al. Síndrome climatérica em uma cidade do Nordeste brasileiro: um inquérito domiciliar Rev Bras Ginecol E: Obstetrícia. 2014; 36: 163-9. PMid:24860975 https://doi.org/10.1590/S0100-7203201400040002

[22] Pérez JAM, Garcia FC, Palacios S, et al. Epidemiology of risk factors and symptoms associated with menopause in Spanish women. Maturitas. 2009; 62: 30-6. PMid:19010615 https://doi.org/10 $.1016 / j$.maturitas .2008 .10 .003

[23] Sabia S, Fournier A, Mesrine S, et al. Risk factors for onset of menopausal symptoms: results from a large cohort study. Maturitas. 2008 Jun 20; 60(2): 108-21. PMid:18513898 https ://doi .org/ $10.1016 / j$. maturitas . 2008.04.004

[24] Mohammadalizadeh Charandabi S, Rezaei N, Hakimi S, et al. Quality of life of postmenopausal women and their spouses: a communitybased study. Iran Red Crescent Med J. 2015; 17(3): e21599. PMid:26019903 https://doi .org/10.5812/ircmj. 21599

[25] Ngai FW. Relationships between menopausal symptoms, sense of coherence, coping strategies, and quality of life. Menopause. 2019; 26(7): 758-64. PMid:30649086 https://doi .org/10.1097/GME. 0000000000001299

[26] Ibrahim Z, Sayed Ahmed WA, El-Hamid SA. Prevalence of menopausal related symptoms and their impact on quality of life among Egyptian women. Clin Exp Obstet Gynecol. 2015; 42(2): $161-7$ 